\title{
Release of Eight Open Source Carrot (Daucus carota var. sativa) Composite Populations Developed under Organic Conditions
}

\author{
Claire H. Luby and Irwin L. Goldman ${ }^{1}$ \\ Department of Horticulture, University of Wisconsin-Madison, 1575 Linden \\ Drive, Madison, WI 53706
}

Additional index words. carrot, Daucus carota, open source, composite population

Over the past several decades, there has been a trend toward increasingly restrictive intellectual property rights (IPR) over plant germplasm including contracts, material transfer agreements (MTA), "bag tag" licenses, plant variety protection (PVP) certificates, and utility patents. This has limited the "freedom to operate" for plant breeders wanting to use a diverse array of germplasm in their breeding programs and has complicated the exchange of plant germplasm around the world (Luby et al., 2015). The goal of many plant breeding programs is to develop cultivars or inbred lines that are genetically stable and homogenous. The goal of breeding the eight populations released here was the opposite: take commercially available cultivars that had freedom to operate for breeding and create diverse carrot populations based on market class and root color. These composite populations are meant to represent some of the diversity present in commercially available carrot germplasm that is available to use in breeding. The populations are the Wisconsin Open Source Composite (WI-OSC) collection: 'WI-OSC Nantes', 'WI-OSC Danvers', 'WI-OSC Chantenay', 'WI-OSC Ball', 'WI-OSC Yellow', 'WI-OSC White', 'WI-OSC Red', and 'WI-OSC Purple'.

To ensure that the diversity present in these populations will remain available for use in breeding and seed production into the future, the WI-OSC populations are being released under the Open Source Seed Initiative (OSSI) Pledge, a mechanism developed by OSSI (contact at: www.osseeds.org) in 2014 to enhance plant breeders' freedom to operate and farmers' and gardeners' ability to

\footnotetext{
Received for publication 10 July 2015. Accepted for publication 14 Aug. 2015.

We thank Steve Pincus and Beth Kazmar of Tipi Produce, Evansville, Wisconsin, and Eric Elderbrock of Elderberry Hill Farm, Waunakee, Wisconsin, for their collaboration in the field production of carrots used in this work. We thank the Clif Bar Family Foundation and Seed Matters for a Seed Matters Fellowship in Organic Plant Breeding. We thank North Central Region Sustainable Agriculture Research and Education and the Ceres Trust for partial support of this project.

${ }^{1}$ Corresponding author. E-mail: ilgoldma@wisc. edu.
}

save and share seed. The OSSI Pledge states: "You have the freedom to use these OSSI-Pledged seeds in any way you choose. In return, you pledge not to restrict others' use of these seeds or their derivatives by patents, or other means, and to include this pledge with any transfer of these seeds or their derivatives (www. osseeds.org)." This means that these populations will serve as reservoirs of carrot diversity that will remain freely available for anyone to use, for whatever purpose, with the condition that when derivatives are created using any of these populations, they will also remain available for others to use and will not be use restricted by IPR. Instead of making germplasm available through a public commons, where resources can be used and appropriated by IPR, the OSSI Pledge creates a "protected commons" around germplasm, ensuring that it remains available to use into the future (Luby et al., 2015).

\section{Origin}

One hundred and forty hybrid, openpollinated and heirloom carrot cultivars commercially available in 2013 were obtained from seed companies and carrot breeders in the United States. Seed of each cultivar was sown in replicated plots on certified organic land at Tipi Organic Produce in Evansville, WI $\left(42.78^{\circ} \mathrm{N}, 89.30^{\circ} \mathrm{W}\right)$, and Elderberry Hill Farm in Waunakee, WI $\left(43.18^{\circ} \mathrm{N}, 89.38^{\circ} \mathrm{W}\right)$, in late June 2013. Roots were harvested in early October and phenotypic data on root characteristics were collected. In addition, information on IPR for each cultivar was assessed based on the ability to use the cultivar in breeding. This included noting whether the cultivar was protected by contract, "bag tag" license, MTA, PVP, or utility patent. Roots from the 87 cultivars with no associated IPR restrictions were selected and advanced for breeding during the winter of 2013-14 (Table 1). Hybrids that were available to use in breeding were included in the composite populations. While sterile plants have been rogued in subsequent cycles of intermating, cytoplasmic male sterility (CMS) continues to be present within the populations.
The eight populations were developed based on market class and root color. Breeding and seed production practices are standard for carrot breeding (Simon, 2000). The market class populations were classified as 'Nantes', 'Danvers', 'Chantenay', and 'Ball' (Fig. 1) and represent those root shapes (Simon, 2000). The root color populations are 'Red', 'Purple', 'White', and 'Yellow' (Table 2; Fig. 2). Roots from a sample of plants of each selected cultivar from the Tipi Organic Produce plots were separated from tops, trimmed, and stored at $4{ }^{\circ} \mathrm{C}$ for 10 weeks. Of each cultivar, $7-10$ roots were planted in pots in the greenhouse in December and grown in a $16-\mathrm{h}$ photoperiod at $20{ }^{\circ} \mathrm{C}$. Roots were separated according to market class categories and colors and grouped accordingly. Each group was placed under an insect-proof netted cage. There was a large attrition rate with many roots rotting or not producing seed. After attrition, each cage contained between 20 and 60 roots and 3 to 19 cultivars depending on the composite. When the primary umbels began to open, house fly (Musca domestica) pupae were placed in each cage at weekly intervals for 6 weeks. Flowering was not completely synchronous among all plants in each cage. However, since plants exhibit 3-5 umbels, a window of time where cross-pollination could occur was achieved in all cages. At seed maturity, seeds were harvested from each plant separately, and a balanced bulk of seed was produced for each composite population for planting in June 2014. Seeds of each composite population were sown in replicated plots at Tipi Organic Produce in Evansville, WI, in 2014. All roots from these plots were harvested in October and stored at $4{ }^{\circ} \mathrm{C}$ for 24 weeks. Roots were transplanted to cages in the field at Tipi Organic Produce in Apr. 2015. When the primary umbels opened, blue bottle fly (Diptera Calliphoridae) pupae were introduced into each cage at weekly intervals for 6 weeks. A balanced bulk of seed was produced for each composite population. The resulting Composite 2 seed of each population is being released through the OSSI Pledge.

\section{Description}

The populations developed to represent different market classes are 'Nantes', 'Danvers', 'Chantenay', and 'Ball' (Table 2; Fig. 1). The 'Nantes' population has orange roots with the typical narrow shoulders, cylindrical shape, and blunt tip that characterize the 'Nantes' shape. Tops range in vigor and were generally less strong than the other populations.

The 'Danvers' population has orange roots that are characterized by the pronounced shoulders and tapered shape of the 'Danvers' type. Tops are very vigorous.

The 'Chantenay' population is orange in color. Roots are characterized by large shoulders with a wide diameter at the crown, tapering, shorter roots than the 'Danvers' type, and a blunt tip. Tops are very vigorous.

The 'Ball' population is orange in color and has generally round, ball-shaped roots. Roots vary slightly in shape with some that 
Table 1. Cultivars with freedom to operate for breeding used in the development of the WI-OSC populations and company from which seed for those cultivars was obtained.

\begin{tabular}{|c|c|}
\hline Population & Cultivars contributing to population and company where seed was obtained in 2013 \\
\hline WI-OSC Danvers & $\begin{array}{l}\text { Rotild (Renee's Garden Seeds), Scarlet Keeper (Fedco, Waterville, ME), James Scarlet Intermediate (Reimer Seeds), Danvers } 126 \\
\text { Half-Long (Burpee's), Sovereign (UW-Madison, Madison, WI), Oranje (UW-Madison), Rolanka (Turtle Tree Seeds, Copake, NY), } \\
\text { Touchon (Cook's Garden Seed, Warminster, PA), Danvers } 126 \text { (High Mowing Organic Seed), Coral II (Evergreen Seeds, } \\
\text { Anaheim, CA), Prodigy (Pinetree Seeds, New Gloucester, ME), St. Valery (Baker Creek, Mansfield, MO), Sweetness III } \\
\text { (Vermont Bean Seed Company, Randolph, WI), Pot o' Gold (Vermont Bean Seed Company), Rodelika (Turtle Tree Seeds), } \\
\text { King Midas (Renee's Garden Seeds), and Rothild (Cook's Garden Seed) }\end{array}$ \\
\hline WI-OSC Chantenay & $\begin{array}{l}\text { Chantenay Royal (Reimer Seeds), Red- Cored Chantenay (High Mowing Organic Seed Company), } \\
\text { Caracas (Johnny's Selected Seeds), Short and Sweet (Burpee's), Sweet Treat (Burpee's), and Big Top (Burpee's) }\end{array}$ \\
\hline WI-OSC Ball & $\begin{array}{l}\text { Parmex (Kitchen Garden Seeds, Santa Fe NM), Round Romeo (Renee's Garden Seeds), Atlas (Johnny's Selected Seeds), } \\
\text { Thumbelina (Kitchen Garden Seeds), Tonda di Parigi (Baker Creek), and Parisienne (Baker Creek) }\end{array}$ \\
\hline WI-OSC Purple & $\begin{array}{l}\text { Cosmic Purple (High Mowing Organic Seed Company), Deep Purple (Johnny’s Seed Company), Dragon (High Mowing } \\
\text { Organic Seed Company), Purple Haze (Johnny's Selected Seeds), and Purple Sun (Kitchen Garden Seed) }\end{array}$ \\
\hline
\end{tabular}

WI-OSC $=$ Wisconsin Open Source Composite.

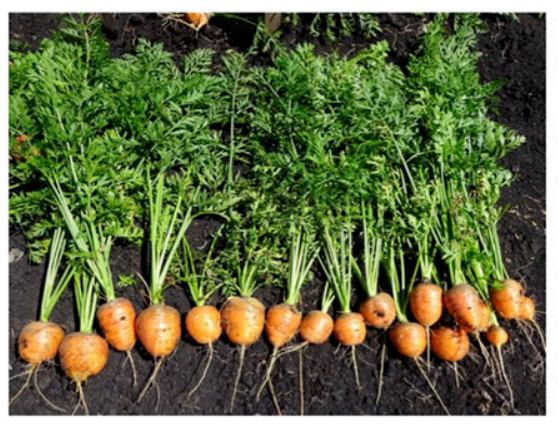

WI-OSC Ball

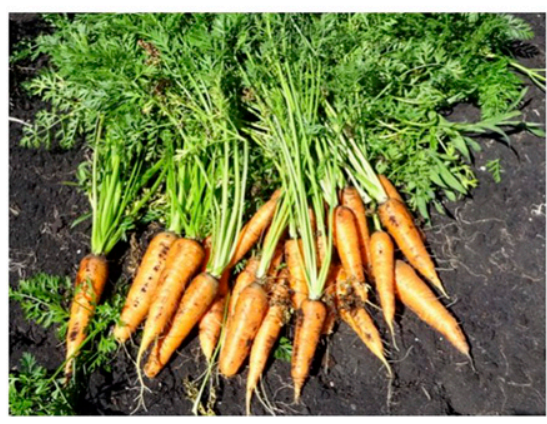

WI-OSC Danvers

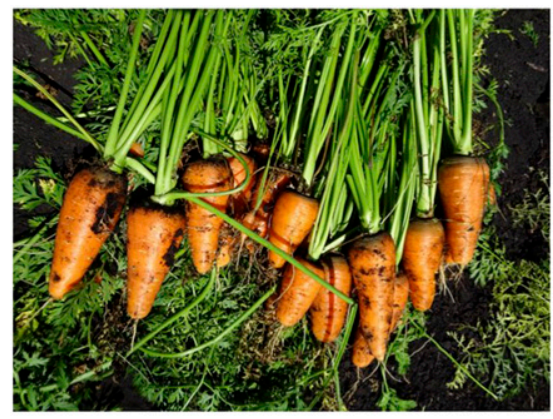

WI-OSC Chantenay

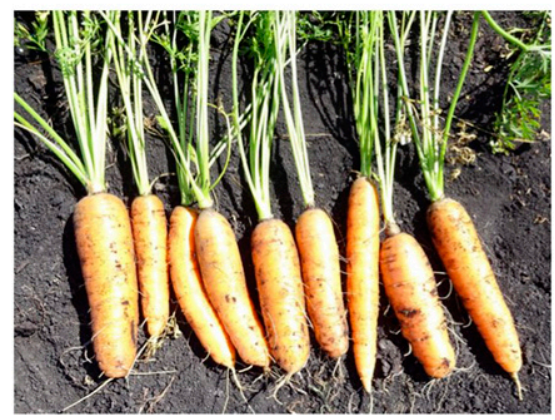

WI-OSC Nantes

Fig. 1. Four Wisconsin open source composite (WI-OSC) populations of different market classes of carrot, clockwise from top left: 'WI-OSC Ball', 'WI-OSC Chantenay', 'WI-OSC Nantes', and 'WI-OSC Danvers'.

are truly round and others that were slightly longer.

The populations characterized by color include the 'Yellow', 'White', 'Red', and 'Purple' populations (Table 2; Fig. 2). Bolting was prevalent in the 'Yellow', 'White', and 'Red' populations. Bolting plants were rogued during the first cycle of selection.

The 'Yellow' population is characterized by variation in the intensity of yellow color, or accumulation of xanthophylls, in the roots with occasional white and orange roots appearing. Some roots have green crowns. Roots vary in shape and are generally 'Danvers' or 'Belgian' with relatively pronounced shoulders and tapered roots. Tops are very strong and vigorous.

The 'White' population is characterized by white-colored roots and green shoulders. Roots are generally 'Belgian' shaped, with large cylindrical roots and tapered tips. This population has very vigorous tops and large roots.
The 'Red' population is characterized by the accumulation of lycopene in the roots, creating an intense red or rose color. Roots are generally 'Danvers' or 'Nantes' in shape, so there is variation in the definition of the root's shoulders, as well as the amount of taper in the roots and tips. Some roots are quite tapered while others are more cylindrical. There is variation in smoothness of roots. Some roots are quite smooth but others have very large lenticels or are prone to branching. Additionally, seed production has proved difficult with this population with many roots rotting during storage or producing unviable seed.

The 'Purple' population has purple exterior color (anthocyanin accumulation) with a variation of purple, orange, and white interiors. Roots are generally quite large in diameter with a significant taper. Tops are very vigorous.

\section{Special Considerations}

These composite populations are not intended to be fully developed cultivars. Instead, they were developed as prebreeding populations with freedom to operate for plant breeding. They are not considered uniform or stable. For example, individual plants in each population exhibit a range of flowering times; thus, there is a degree of reproductive asynchrony within populations. As the composite populations undergo more cycles of selection, we expect storability and flowering time to be a selection target as a result of the system of seed production. These composite populations were produced on an organically certified farm and breeding out of these populations for development of cultivars useful for organic production systems may be one potential future use.

Hybrid cultivars were included in the development of these composite populations. Since CMS is used in hybrid development of carrot, there is sterile cytoplasm present 
Table 2. Average root length, average root diameter, and population color of the composite 1 generation of the eight WI-OSC populations grown at Tipi Organic Produce in 2014.

\begin{tabular}{lccl}
\hline Population & $\begin{array}{c}\text { Avg root length }(\mathrm{cm}) \\
\text { of 20 roots } \pm \mathrm{SE}\end{array}$ & $\begin{array}{c}\text { Avg root diam }(\mathrm{cm}) \\
\text { measured at the } \\
\text { crown } \pm \mathrm{SE}\end{array}$ & \multicolumn{1}{c}{$\begin{array}{c}\text { Color and pigment } \\
\text { accumulation }\end{array}$} \\
\hline WI-OSC Nantes & $14.6 \pm 0.4$ & $3.3 \pm 0.1$ & Orange-carotenoid \\
WI-OSC Danvers & $15.3 \pm 0.4$ & $4.0 \pm 0.2$ & Orange-carotenoid \\
WI-OSC Chantenay & $12.1 \pm 0.6$ & $4.6 \pm 0.2$ & Orange-carotenoid \\
WI-OSC Ball & $4.9 \pm 0.2$ & $4.4 \pm 0.2$ & Orange-carotenoid \\
WI-OSC Yellow & $20.8 \pm 0.4$ & $4.0 \pm 0.2$ & Yellow-Xanthophyll \\
WI-OSC White & $22.0 \pm 0.8$ & $3.6 \pm 0.2$ & White-no pigment accumulation \\
WI-OSC Red & $18.7 \pm 0.8$ & $3.5 \pm 0.2$ & Red-lycopene \\
WI-OSC Purple & $15.8 \pm 0.6$ & $4.5 \pm 0.2$ & Purple exterior, orange \\
& & & interior-anthocyanins, \\
& & & carotenoids, respectively \\
\hline
\end{tabular}

WI-OSC $=$ Wisconsin Open Source Composite.

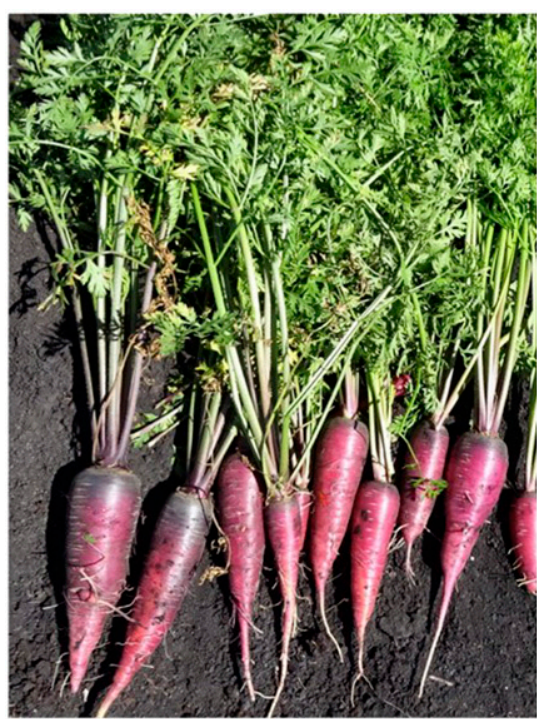

WI-OSC Purple

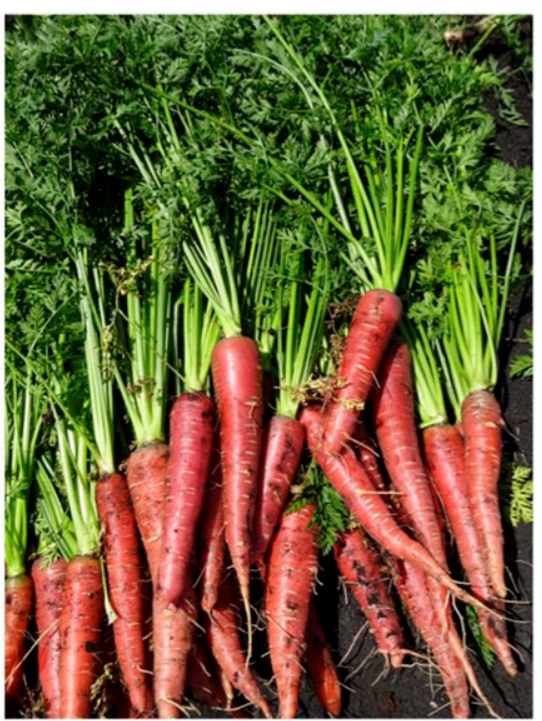

WI-OSC Red

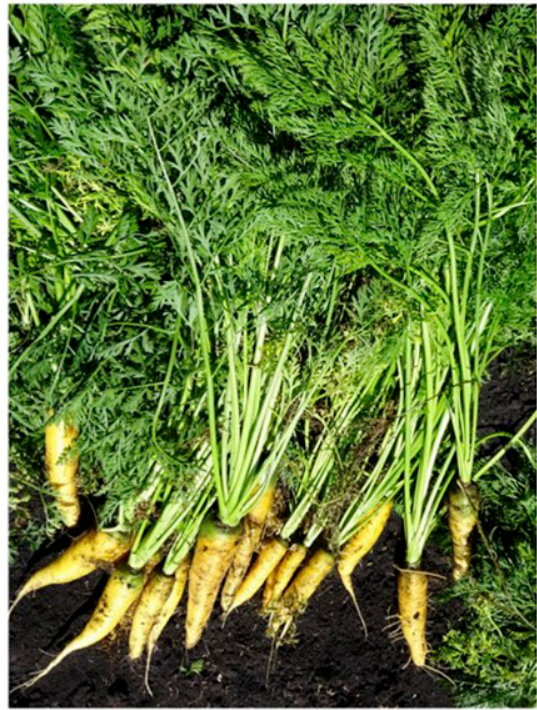

WI-OSC Yellow

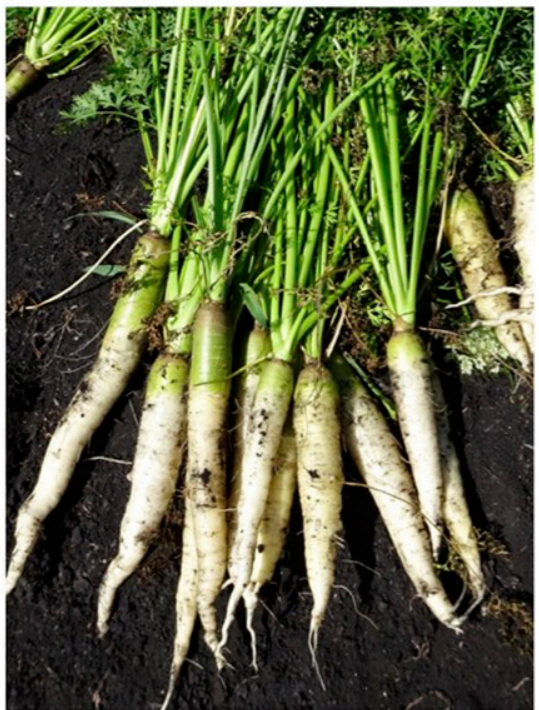

WI-OSC White
Fig. 2. Four Wisconsin open source composite (WI-OSC) populations of different root colors of carrot, clockwise from top left: 'WI-OSC Purple', 'WI-OSC Red', 'WI-OSC White', and 'WI-OSC Yellow'. in these composite populations. We wanted to ensure that the diversity present in hybrid cultivars was represented in these composite populations. Some sterile plants have been rogued from the second generation of seed production; however, we expect that sterile plants will continue to be present in subsequent generations since the presence of sterile cytoplasm may be masked by the presence of restorer alleles.

Finally, we recognize that certain forms of IPR, such as PVP, do allow for breeding and so could have been included in a foundation composite population in this project. However, none of the carrots included in this study were protected by PVP. Additionally, because PVP has some restrictions on distribution of saved seed, we would hesitate to incorporate PVP-protected material in open source breeding material.

\section{Availability}

Seeds of these Composite 2 populations are being released by the University of Wisconsin-Madison carrot breeding program through the Open Source Seed Initiative Pledge (www.osseeds.org).

\section{Literature Cited}

Luby, C.H., J. Kloppenburg, T.M. Michaels, and I.L. Goldman. 2015. Enhancing freedom to operate for plant breeders and farmers through open source plant breeding. Crop Sci. 55(3).

Simon, P.W. 2000. Domestication, historical development, and modern breeding of carrot. Plant Breeding Rev. 19:157-190. 